\title{
Oil Price Shocks and Inflation Dynamics in Nigeria: Sensitivity of Unit Root to Structural Breaks
}

\author{
Joseph Chukwudi Odionye ${ }^{1, *}$, Okanta Sunday Ukeje ${ }^{2}$, Augustine Chika Odo ${ }^{3}$ \\ ${ }^{1}$ Department of Economics, Faculty of Business Administration, Abia State University, Uturu, Nigeria \\ ${ }^{2}$ Department of Banking and Finance, Faculty of Business Administration, Abia State University, Uturu, Nigeria \\ ${ }^{3}$ Department of Economics, Faculty of Management and Social Sciences, Godfrey Okoye University, Enugu, Nigeria
}

Email address:

josephodionye@yahoo.com (J. C. Odionye)

${ }^{*}$ Corresponding author

\section{To cite this article:}

Joseph Chukwudi Odionye, Okanta Sunday Ukeje, Augustine Chika Odo. Oil Price Shocks and Inflation Dynamics in Nigeria: Sensitivity of Unit Root to Structural Breaks. International Journal of Business and Economics Research. Vol. 8, No. 2, 2019, pp. 58-64. doi: 10.11648/j.ijber.20190802.13

Received: January 3, 2019; Accepted: February 22, 2019; Published: May 17, 2019

\begin{abstract}
Motivated by the prevalence of misleading inference in time series occasioned by failure to account for structural breaks in series as volatile as oil price in Nigerian specific studies, this study sought to find out whether structural breaks matter in studying the response of inflation to oil price shocks. The study employed Zivot-Andrews unit root test with structural break to compare the unit root result with the conventional ADF result while the local projection impulse response function (LPIRF) was used to determine the response of inflation dynamics to oil price shocks in Nigeria from 1981 to 2016. The unit root test shows that failure to account for structural break in unit root of a volatile series can produce wrong inference. The LPIRF results suggestedthat inflation responds significantly to oil price shocks and that there exists a higher persistence level of oil price shocksin exchange rate than inflation. Furthermore, the counterfactual result conditioned on global oil market behavior shows that inflation responds significantly to oil price due to global oil market behavior.
\end{abstract}

Keywords: Oil Price, Inflation Dynamics, Shocks, Structural Break, Impulse Response

\section{Introduction}

The effect of oil price shocks on inflation has been a matter of great concern to policymakers in both oil exporting and oil importing countries. Oil price shocks is widely believed to have majoreffects on macroeconomic variables but the effects differ from country to country depending whether the country is oil exporting or oil importing country. Theoretically, oil price increase leads to economic boom in oil exporting countries as government increases its aggregate spending and aggregate demand due to increase in revenue. On the contrary, decline in oil price can lead to economic recession due mainly to reduction in aggregate demand. This theoretical postulation has led to diverse research works on the nature of the relationship between oil price shocks and macroeconomic variables in advanced countries example [1, 2, 3, 4 and others].

Although a growing body of works exist which study the effects of oil price shocks in developed countries and oil importing countries, only few attempts have been made in oil exporting developing countries [5-9]. Most of these studies employed traditional VAR and Structural VAR models. These models rely on impulse responses and variance decomposition for interpretation as the coefficients of VAR and SVAR are always impossible to interpret. Impulse responses generated from VAR and SVAR models are biased and inconsistent [10-12].

Furthermore, almost all the previous empirical studies on oil price shocks in Nigeria failed to account for structural break in the unit root test. Failure to allow for an existing structural break in the series leads to a bias that reduces the ability to reject a false unit root null hypothesis [13-14]. This can produce misleading results leading to incorrect inference. Oil price shocks come with a drift in key macroeconomic variables and if these drifts in variables are not accounted for in unit root, the result is biased and misleading which leads to 
incorrect inference.

The recent dwindling in global crude oil prices which started in July 2014 has adversely affected Nigeria, especially in the areas of foreign reserves, currencies crisis, declining government revenue, and ultimately threat in terms of ability to meet financial obligations as and when due. Oil price fell from its all time high of USD105.87 in 2013 to USD 96.29 in 2014 and further fell to USD40.76 [15]. This means between 2013 and 2016 oil price declined sharply by more than half $(64.5 \%)$. The resultant effect has been a large outpour of policies among policy makers and debate among economists on the best policy intervention to reverse the situation.

In response to this, the Nigerian government devalued its currency by $8 \%$ from N155 to N168 in October 2015, the Nigerian official exchange rate depreciated from N168 in October, 2015 to N347.25 in August 2016 representing about 106.7 per cent in less than one year [16]. During this period, the year-on-year inflation rate jumped from $9.3 \%$ in October, 2015 to 17.6 percent in August 2016. This is the highest reading since 2005 , as cost of housing, food and nonalcoholic beverages and transport surged mostly due to rising import cost occasioned by a weak naira.

Thus, this study sought to examine the oil price shocks and inflation dynamics while accounting for structural break in the model variables in Nigeria. The remaining part of this work is divided into four sections. Section two discusses the theoretical literature, section three discusses the methodological issues and section four presents and discusses the empirical results while section five highlights policy implications and conclusions

\section{Literature Review}

Many researches on the effect of oil price shocks on inflation exist in both developed and developing countries with no consensus on the nature of relationship. Mohaghegh and Mehrara investigation ofchanges in oil prices on macroeconomic variables in oil exporting countries employing Panel data analysis in VAR framework [17]. Their result showed that oil shocks are not necessarily inflationary but rather domestic policies are. Furthermore, they reported money as the key factor responsible for macroeconomic changes.

In a similar study but with different approach, the theoretically examination of the influence of oil price fluctuations on macroeconomic variables in OECD and nonOECD countries was examined [18]. The result of the report showed volatility in oil prices as a source of major problem of economic growth as it has negative influence on macroeconomic variables. Their results also showed oil price fluctuation as having negative influence on major macroeconomic variables such as total intake, level of investment, rate of unemployment and inflation mainly in non-OECD countries

Employing Ordinary Least Square and Granger Causality Test, the investigation of oil price volatility and economic development nexus was carried out in Nigeria[7]. The outcome of their findings suggests the existence of significant influence of oil price shocks on major macroeconomic variables such as real GDP, inflation, interest rate and exchange rate in Nigeria. In a related study, Apere and Ijomahemployed VAR and EGARCH models to investigate effects of oil price on macroeconomic variables in Nigeria using a higher frequency data [9]. They reported one direction of causality running from oil price to exchange rate and interest. In the case of real GDP, they reported it not significantly influenced by oil price movement.

On their own, Taiwo, Abayomi and Damilareemployed Johasen Cointegration Test and error correction model techniques to examine the influence of oil price fluctuations on some selected macroeconomic variables [8]. Their research showed a significant relationship between the variables. In addition, the result showed that oil price, stock price and exchange rate have significant effect on the economy of Nigeria. The asymmetric effects of oil price shocks on output and prices in Nigeria using a structural VAR model between 1990 and 2008 was examined by Mordi and Adebiyi [19]. The result of their finding shows that the oil price shocks on output and prices is asymmetric in nature with the impact of oil price decrease significantly greater than oil price increase.

In another related study, the impact of oil price fluctuation on the Ghanaian economy was investigated byBondzie, Bertolomeo and Fosu [20]. Based on the features of its economy, they employed dynamic stochastic general equilibrium (DSGE) model and their results show a persistent effect of world oil price and monetary policy shocks on economic growth. It further shows that a shock on interest rate leads to a sharp fall in prices.

Most recently, the study of Abdulkareem and Abdulhakeemprovides an analytical insight on modeling macroeconomics and oil price volatility in Nigeria [21]. They employed quarterly data within the multivariate GARCH model. Their result shows that all the macroeconomic variables considered (RGDP, interest rate, exchange rate, oil prices) are volatile and they concluded that oil price is a major source of shocks to macroeconomic variables in Nigeria.

In another development, Imobighestudied the impact of oil price instability on the growth process of the Nigerian economy between 1970 and 1997 [22]. He employed simple regression technique and found a positive and significant relation between GDP and oil prices. The impact of crude oil price volatility on economic growth in Nigeria between 1980 and 2014 was examined by Nwanna and Eyedayi[23]. They employed ordinary least square (OLS) technique and their results show a positive and significant relationship between oil price and economic growth in Nigeria.

A study carried out in Libya to examine the effects of fluctuations of oil price on economic growth using annual data from 2000 to 2015 observed sharp movements in the prices of oil as an important source of economic fluctuation in the world economy [24]. The study employed VAR model and Johansen cointegration technique to examine the effects 
of fluctuation on output. He found out that there is no long run relationship between oil prices and economic growth. He further reports that oil price has a positive and statistical significant impact on economic growth in Libya.

\section{Data and Methodological Issues}

The data for this work were sourced from [25]. The study employed Local Projection Impulse Response Function due to [10] and modified by [26] to examine the response of inflation dynamics to oil price shocks in. The LPIRF was introduced by [10] as an alternative to impulse function generated by VAR and has been widely used because of its advantages over VAR. LPIRF uses a new set of estimates for each horizon and thus avoids escalation of the misspecification error through the non-linearity of the standard VIRFs technique as $h$ increase and $h>1$. The advantages of LPIRF over VAR are: (i) it is more robust to misspecification, (ii) it does not involve the same nonlinearity as VAR and hence are more likely to be well approximated by Gaussian distribution, in contrast to VAR and SVAR, assumptions on the structure are not needed (iv) it can be estimated by simple regression and (v) it does not require identification $[10,11,12,27]$.

The general form of an impulse response function is given below:

$$
\operatorname{IRF}\left(\mathrm{t}, \mathrm{h}, \mathrm{d}_{i}\right)=E\left[y_{t+h} \mid \mu_{t+h}\left\{\begin{array}{l}
d_{i} \text { if } j=0 \\
0 \text { if } j \in[1, \mathrm{~h}]
\end{array}\right\} ; \mathrm{I}_{t}\right]-E\left[y_{t+h} \mid \mu_{t+h}=0 \forall \mathrm{j} \in[0, \mathrm{~h}] ; \mathrm{I}_{t}\right]
$$

Thus IRFs measure the reaction of the system's variables at $t+h$, for $h=0,1, \ldots, H$ to a shock of the disturbance vector of $d_{i}$. $\mathrm{I}_{\mathrm{t}}$ is the information available at $\mathrm{t}$ which is the set of lagged dependent variable vectors up to lag order $\mathrm{p}$.

In view of the above the LPIRF is specified as

$$
I R F_{t+h}-I N F_{t}=\alpha_{i}^{h}+\delta^{h} \Delta S_{t-1}+\sum_{i=1}^{p} \delta_{1, j}^{h} \Delta S_{j-j}+\sum_{j=0}^{p} \phi_{1, j}^{h} \Delta O P R_{t-j}+\sum_{j=1}^{p} \phi_{2, j}^{h} \Delta I N F_{t-j}+\sum_{j=0}^{h-1} \delta_{2, j}^{h} \Delta \mathrm{S}_{t-h-j}+\sum_{j=0}^{h-1} \phi_{3, j} \Delta O P R_{t+h-j}+\varepsilon_{t}^{h}
$$

Where $\mathrm{INF}=$ inflation rate, $\mathrm{OPR}=$ oil price, $\mathrm{h}$ represents time horizon $(\mathrm{h}=0,1, \ldots \mathrm{H}), \Delta \mathrm{St}$ represents shocks variables caused by variables other than oil price (monetary policy shock), $\delta^{\text {h }}$ represents the cumulative effects on inflation, where $\mathrm{h}$ denotes the time horizon, the third and fourth terms account for shocks in inflation dynamics and other factors occurring before time $\mathrm{t}$ but may have influence on the inflation outcomes in the country, the coefficient of $\mathrm{INF}_{\mathrm{t}-\mathrm{j}}$ explains the effects inflationcaused by its own lagged. The fifth and sixth terms introduced by [26] account or the effects of oil price shocks and other variables occurring between $t$ and $\mathrm{t}+\mathrm{h}$ that affect inflation at time $\mathrm{t}+\mathrm{h}$.

\section{Estimation Procedure}

Prior to the LPIRF, the mean reversion test of the series was carried out using Zivot-Andrew (Z-A) unit root test. But before Z-A unit root test with structural break is carried out, we first for the existence of structural in the model variable using [28] multiple break point test. Several studies have found that the conventional unit root tests fail to reject the unit root hypothesis for the series that are actually stationary with a structural break, not even for a study of oil price that is volatile [13 and 14].

Zivot-Andrews Unit Root Test:

$$
\begin{gathered}
I N F_{t}=\mu+\phi D U_{t}(\lambda)+\beta t+\gamma D T_{t}^{*}(\lambda)+\alpha I N F_{t-1}+\sum_{j=1}^{k} \gamma_{j} \Delta I N F_{t-j}+\varepsilon_{t} \\
O P R_{t}=\mu+\phi D U_{t}(\lambda)+\beta t+\gamma D T_{t}^{*}(\lambda)+\alpha O P R_{t-1}+\sum_{j=1}^{k} \gamma_{j} \Delta O P R_{t-j}+\varepsilon_{t} \\
E X R_{t}=\mu+\phi D U_{t}(\lambda)+\beta t+\gamma D T_{t}^{*}(\lambda)+\alpha E X R_{t-1}+\sum_{j=1}^{k} \gamma_{j} \Delta E X R_{t-j}+\varepsilon_{t}
\end{gathered}
$$

Where $D U_{t}(\lambda)=1$, if $\mathrm{t}>\mathrm{T} \lambda, 0$ otherwise; $D T_{t}^{*}(\lambda)=\mathrm{t}-$ $\mathrm{T} \lambda, 0$ otherwise. $\mathrm{INF}=$ inflation rate, $\mathrm{OPR}=$ oil price and $\mathrm{EXR}=$ exchange rate. The null hypothesis of Z-A unit root test is that the variable has unit root with structural break either in the intercept, trend or both. The decision rule is to reject the null hypothesis if computed $t$ statistics is greater than the critical value.

To estimate the LPIRF model, we first run a VAR model with the maximum lag length and then select the optimal lag length based on information criteria. Then we estimated the LPIRFs. To avoid the problem of serial correlation that is usually associated with IRFs, in line withJorda, we introduced two sets of conditional bands to represent uncertainty about the shape of the LPIRFs and to examine the individual significance of the coefficients in a given trajectory [29]. Then we imposed restrictions on impulse response and test for their significance level. Two significant tests are "joint" and "cumulative." "Joint" refers to the null hypothesis that all the 
response coefficients are jointly zero while "cumulative" refers to the null that the accumulated impulse response after included periods is zero. Lastly we carried out counterfactual analysis to enable us know the response of a inflation dynamics to oil price shock due to conditioning path.

\section{Results and Discussion}

\subsection{Analysis of Structural Breaks}

Given several economic crises and oil price shocks, changes in institutional arrangements macroeconomic variables are subjected to structural breaks. Thus we tested for the presence of structural break in each of the series using multiple break point test by Bai and Perron [28]. The null hypothesis is that there is no structural break $(\mathrm{m}=0)$ in the series versus the alternative hypothesis that there are $\mathrm{m}=\mathrm{k}$ number of structural breaks in the series. The decision rule is to reject null hypothesis if the Bai-Perron F-statistics is greater than its critical value. The summary of the result is presented in table below.

Table 1. Summary of Bai-Perron Multiple Breakpoint Test.

\begin{tabular}{lll}
\hline Variables & M & T \\
\hline OPR & 2 & $1986 \& 2014$ \\
INF & 3 & $1986,2009 \& 2016$ \\
EXR & 1 & 1986 \\
\hline
\end{tabular}

$\mathrm{M}$ represents the number of structural breaks in the series, $\mathrm{T}$ represents the periods of structural breaks

Source: Computed by the Author using E-views 9.0

The summary of Bai-Perron multiple breakpoint test in table 1 shows that multiple breaks characterized the macroeconomic variables in Nigeria. The structural break dates characterising key macroeconomic variables highlighted the introduction of structural adjustment program (SAP) in 1986. Single break period of 1986 occurs in key variable like real exchange rate highlighting the SAP and the first trade liberalization policy in Nigeria. Oil price (OPR) had two break periods 1986 and 2014. These periods coincide with the oil price shock: in 1986, there was a collapse of oil market leading to oil price decline and 2014 saw the emergence ofthe global oil price dwindling that the oil market is yet recover from. Inflation rate (INF) had three major breaks which characterized the period of SAP of 1986 and 2009 where major policy reforms were introduced in Nigeria.

In order to account for these structural breaks, we employed Zivot and Andrewsunit root test with structural breaks in both trend and intercept to determine the time series properties of the model variables [30].

\subsection{Unit Root Tests}

Most time series data tend to contain infinite variances that are not mean reverting and lie on the unit circle. It is however observed that estimation made from such series is usually resulting in spurious regression that makes little or no economic sense [31, 32]. Thus, each of the variables was examined to determine their order of integration. The null hypothesis for both Zivot-Andrews and ADF are that the variable under investigation has a unit root against the alternative that it does not. The decision rule is to reject the null hypothesis if the tstatistic value exceeds the critical value at a chosen level of significance (in absolute term). The summaries of the results of the unit root test are presented in table 2 below:

Table 2. Summary of Zivot-AndrewsVs ADF Unit Root Test.

\begin{tabular}{|c|c|c|c|c|c|c|c|c|}
\hline \multirow{2}{*}{ Variable } & \multirow{2}{*}{$\begin{array}{l}\text { ADF Test } \\
\text { Statistics }\end{array}$} & \multicolumn{2}{|c|}{ ADF Critical Value } & \multirow{2}{*}{$\begin{array}{l}\text { Order } \\
\text { ofIntegration }\end{array}$} & \multirow{2}{*}{$\begin{array}{l}\text { Zivot-Andrews } \\
\text { Statitics }\end{array}$} & \multicolumn{2}{|c|}{ Z-ACritical Value } & \multirow{2}{*}{$\begin{array}{l}\text { Order of } \\
\text { Integration }\end{array}$} \\
\hline & & $1 \%$ & $5 \%$ & & & $1 \%$ & $5 \%$ & \\
\hline OPR & $-5.3512 * *$ & -3.6329 & -2.9484 & $\mathrm{I} \sim(1)$ & $-5.43 *$ & -5.67 & -4.93 & $\mathrm{I} \sim(0)$ \\
\hline INF & $-3.7245 * *$ & -3.6394 & -2.9511 & $\mathrm{I} \sim(1)$ & $-6.09 * *$ & -5.34 & -4.91 & $\mathrm{I} \sim(0)$ \\
\hline EXR & $-4.6157 * *$ & -3.6394 & -2.9511 & $\mathrm{I} \sim(1)$ & $-5.10^{*}$ & -5.48 & -4.93 & $\mathrm{I} \sim(1)$ \\
\hline
\end{tabular}

Figures in parenthesis are critical values. $* *(*)$ denote statistical significant at $1 \%$ and $5 \%$ levels of significance respectively. I(d) denotes the order of integration of a variable. Source: Computed by the Author using E-views 9.0

Obviously, the result from table 2 shows that all the variables are integrated of one (stationary at first difference) when ADF was used to test for unit root while the result of ZA shows that except exchange rate (EXR), the variables are integrated of order zero. This therefore suggests that failure to account for structural change, we tend to reject the null hypothesis of stationarity when actually we are to accept, supporting the assertion ofPerron [13-14]. This result suggests that structural breaks matter in testing for unit root of a series as volatile as oil price.

\subsection{Transmission of Oil Price Shocks to Inflation Using LPIRFS}

The solid green lines with circles are the regular VAR impulse response function (VIRF) while the remaining solid lines are the LPIRF with associated marginal error bands at 95\% confidence bands. The LPIRF result shows an instant negative response of inflation to oil price shock at the first two periods before it responds positively but infinitesimally for a longer period. In the case of exchange rate, it responds 
negatively and exponentially to oil price shocks from the first period and the shock seems to persist for a longer time (see Appendix).

\subsection{Response of Inflation Dynamics Due to Conditioning Path}

In line with [29], we created a conditioning response path in order to examine the change in system's behavior. We impose a restriction on the response of inflation to oil price shocks by substracting 0.25 points from every coefficient. Solid (blue) lines with squares and associated dashed (blue) lines are the original impulse responses with conditional error bands. Solid (red) line with the circles is the counterfactual response in the bottom graph, whereas it denotes the conditional response given this counterfactual in the top panel.

\section{Response of OPR to shock in OPR}

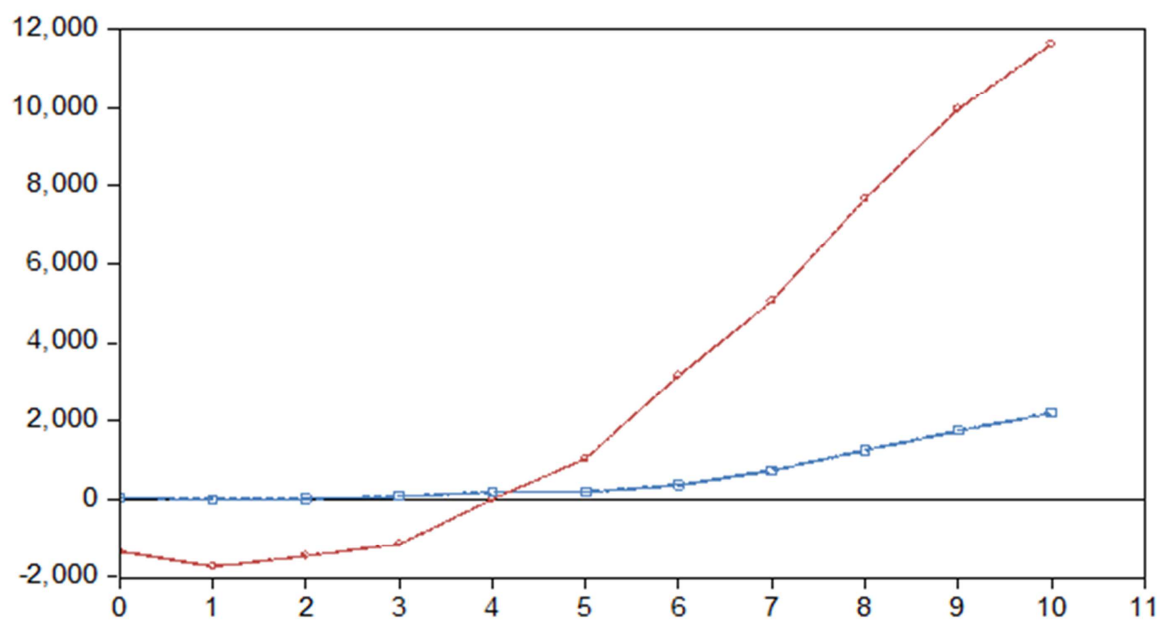

Counterfactual: Response of INF to shock in OPR

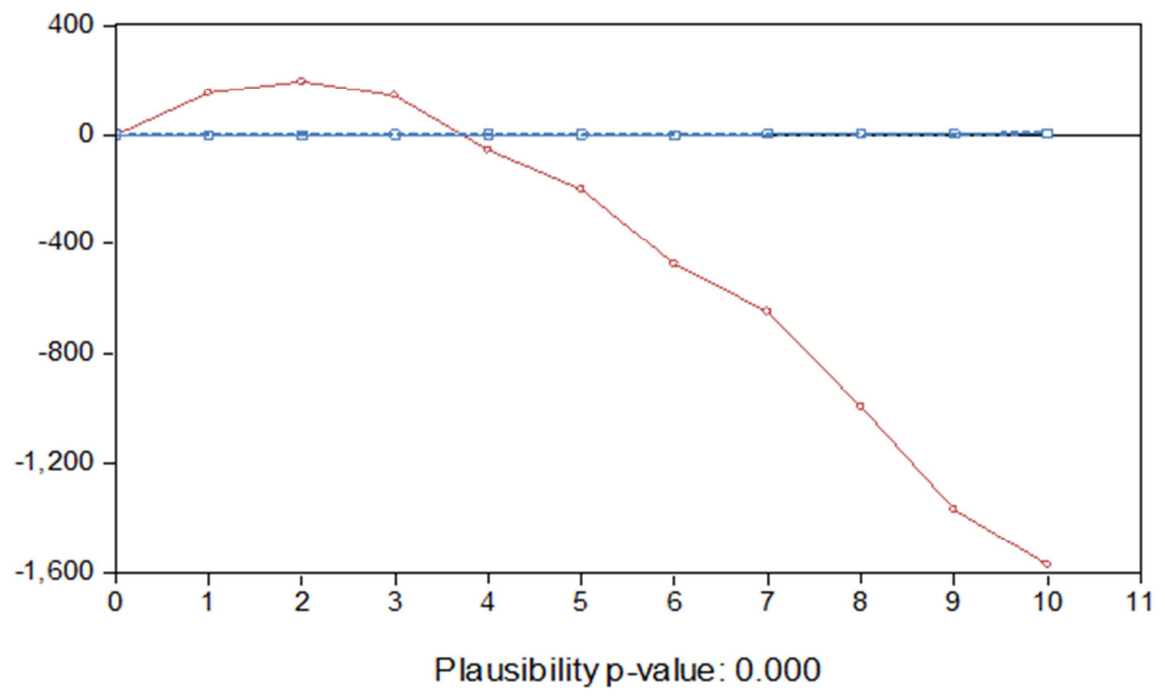

Figure 1. Response of Inflation Dynamics Due to conditioning Path.

The above figure is the response of inflation to oil price shocks due to global oil market behavior. The p-value measures the distance between the conditioning event and the sample estimates [29]. From the result, obviously inflation responds significantly to oil oil price shocks in Nigeria due to global oil market behavior since the p-value is less than 0.05 .

\section{Conclusions and Policy Implications}

The result of unit root test suggests that structural breaks matter in testing for unit root of a series as volatile as oil price. The result of LPIRF shows that inflation responds instantaneously and negatively to oil price shock before responding positively but insignificantly to oil price drift. Also, exchange rate responds negatively and exponentially to oil price shocks from the first period and the shock seems to persist for a longer time. The empirical results further show a significant transmission of oil price shocks to inflation dynamics in Nigeria. 


\section{Appendix}

Local Projection Impulse Response Function
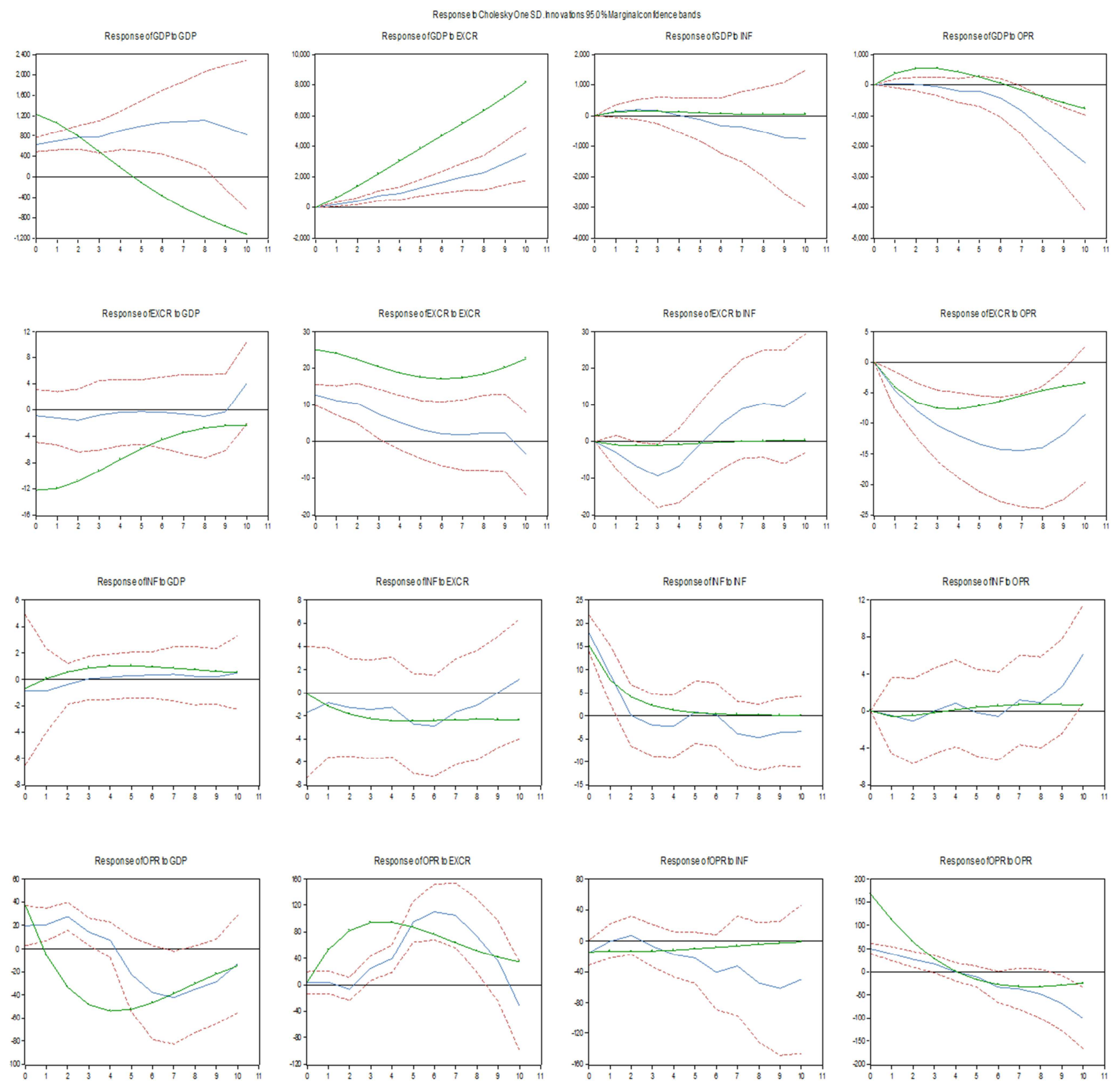

Figure 2. Local Projection Impulse Response Function (LPIRF).

University of Califonia. San Diego.

\section{References}

[1] Hamilton, J. D. (1983). Oil and the macroeconomy since the World War II. Journal of Politcal Economy, 91 (2), 228-248.

[2] Hamilton, J. D. (1996). This is what happened to oil price Macroenonomy relationship. Journal of Monetary Economics, 38 (1996), 215-220.

[3] Hamilton, J. D. (2009). Causes and consequences of the oil shock of 2007-08. NEBR Working paper No 15002.

[4] Hamilton, J. D. (2010). Nonlinearities and the macroeconoic effects of oil prices. Working Paper Series. University of Califonia. San Diego.

[5] Ekpo, A. O. (2009). Oil price shocks and Nigeria's macro economy. Research Paper, University of Ibadan, Ibadan.

[6] Aliyu, S. U. R. (2009). Impact of oil price shocks and exchange rate volatility on economic growth in Nigeria: An empirical investigation. MPPR, Paper No. 16319. Retrieved from http://mpra.ub,uni-muenchen.de/16319. 
[7] Wilson, A. David, U. Inyiama, O. \& Beatrice, E. (2014). Oil price volatility and economic development: Stylized evidence in Nigeria. Journal of Economics and International Finance, 6(6), 125-133.

[8] Taiwo, M., Abayomi, T. \&Damilare O. (2012). Crude Oil Price, Stock Price and Some Selected Macroeconomic Indicators: Implications on the Growth of Nigeria Economy, Research Journal of Finance and Accounting, 3(2), 42-48.

[9] Apere O. \&Ijomah A. M. (2013). Macroeconomic Impact of Oil Price Levels and Volatility in Nigeria. International Journal of Academic Research in Economics and Management Sciences 2(4), 15-25.

[10] Jorda, O. (2005). Estimation and inference of impulse responses by local projections. American Economic Review, 161-182.

[11] Jorda, O. (2007). Joint Inference and counterfactual experimentation for impulse response function by local projection." University of California (Davis) Working Paper series, 06-24.

[12] Ronayne, J. B. (2011). Which Impulse Response Function? Warwick Economic Research Paper No 971.

[13] Perron, P. (1989). The great crash, the oil price shock, and the unit root hypothesis. Econometrica, 57, 1361-1401.

[14] Perron, P. (1997). Further evidence on breaking trend functions in macroeconomic variables. Journal of Economtrics, 80 (2), 251-270.

[15] OPEC (2016). Organization of Petroleum Exporting Countries Annual data.

[16] CBN (2016). Revised Guidelines for the operation of the Nigerian Inter-bank Foreign Exchange Market (IFEM). $15^{\text {th }}$ June, 2016.

[17] Mohaghegh, M. \&Mehrara, M. (2011). Macroeconomic Dynamics in the Oil Exporting Countries: A Panel VAR study. International Journal of Business and Social Science, 2(21), 288-295.

[18] Ebrahim, Z., Inderwildi, O. R. \& King. D. A.(2014). Macroeconomic impacts of oil price volatility: mitigation and resilience, Front Energy review, 288-295.

[19] Mordi, C. N. O. and Adebiyi, M. A. (2010). The Asymetric Effects of Oil Price Shocks on Output and Prices in Nigeria using a Structural VAR Model. Economic and Financial Reviews, 48 (1), 1-32.
[20] Bondzie, E. A., Bertolomeo, G. D. and Fosu, G. O. (2014). "Oil Price Fluctuations and it Impact on Economic Growth: A Dsge Approach." International Journal of Academic Research in Business and Social Siences, 2 (2), 217-242.

[21] Abdulkareem, A. and Abdulhakeem, K. A. (2016). "Analysing Oil Price-Macroeconomy Volatility in Nigeria." CBN Journal of Applied Statistics in Nigeria, 7 (1), 1-22.

[22] Imobighe, M. D. (2015). "The Impact of Oil Price Instability on the Growth Process of the Nigerian Economy." Journal of Resources Development and Management, 14 (2015), 56-70.

[23] Nwanna, O. I and Eyedayi, A. M. (2016). "Impact of Crude Oil Price Volatility on Economic Growth in Nigeria." IOSR Journal of Business and Management, 18 (6), 10-19.

[24] Aimer, N. M. M. (2016). "The Effect of Fluctuations of Oil Price on Economic Growth of Libya." Energy Economics Letters, 3 (2), 17-29.

[25] Central Bank of Nigeria Statistical Bulleting (2016). CBN annual data.

[26] Teulings, C. N. and Zubanov, N. (2014). Is economic recovery a myth? Robust estimation of impulse response. Journal of Applied Econometrics, 29 (3), 497-514.

[27] Caselli, F. G and Roitman, A. (2016). Non-linear exchange rate pass-throughin Emerging markets. International Monetary Fund (IMF) Working Paper No. 16/1 pp 1-36.

[28] Bai, J. and Perron, P. (2003a). Computation and analysis of multiple structural change models. Journal of Applied Economerics, 18, 1-22.

[29] Jorda, O. (2009). Simultaneous confidence regions for impulse response function. Review of Economics and Statistics, 91 (3), 629-647.

[30] Zivot, E. and Andrews, K. (1992). Further evidence on the great crash, the oil price shock, and the unit root hypothesis. Journal of Business and Economic Statistics, 10 (10), 251270.

[31] Granger C and Newbold (1974), Spurious Regression in Econometrics, Journal of Econometrics 2 (2), 111-120.

[32] Dickey, D. A and Fuller, W. A. (1981). Likelihood ratio statistics for autoregressive time series with a unit root. Econometrica, 49 (4), 1057-1072. 